\title{
HTLV-I proviral load in Argentinean subjects with indeterminate western blot patterns
}

\author{
Andrea Mangano ${ }^{*}$, Natalia Altamirano ${ }^{1}$, Mirta Remesar², María B Bouzas ${ }^{3}$, Paula Aulicino ${ }^{1}$, Inés Zapiola², \\ Ana D Pozo ${ }^{2}$, Luisa Sen ${ }^{1}$ \\ From 15th International Conference on Human Retroviruses: HTLV and Related Viruses \\ Leuven and Gembloux, Belgium. 5-8 June 2011
}

\section{Background}

A considerable high proportion of HTLV-I/II seroindeterminate blood donors have been documented in many countries including Argentina. In 5-10\% of indeterminate Western Blot (WB) cases proviral sequences are detected. The aim of the study was to evaluate HTLV-I proviral load $(\mathrm{pVL})$ in WB indeterminate PCR positive cases.

\section{Methodology}

A total of 87 indeterminate WB samples (HTLV blot 2.4 assay- Genelabs Diagnostics-) were studied over a 10 year period referred from the Blood Bank at Garrahan Hospital $(n=83)$ and from the Virology Unit at Muñiz Hospital $(n=4)$. HTLV-I and -II tax and pol proviral sequences were amplified by in-house nested PCR assays. HTLV-I pVL was estimated by a quantitative real-time PCR assay targeting the HTLV-I pol gene and the albumin gene as normalizer. The limit of detection of the assay was $2.6 \log 10$ copies of HTLV-I/106 PBMCs (0.04\% copies/100 PBMCs).

\section{Results}

In $8 / 87$ samples HTLV proviral sequences were amplified, 7 HTLV-I and one HTLV-II. Proviral load was detectable in 4 of the 7 HTLV-I positive samples ranging from $2.72 \log 10$ copies/106 PBMCs $(0.05 \%)$ to 4.65 $\log 10$ copies/106 PBMCs (4.5\%), but was undetectable in the remaining $3(<0.04 \%)$. One of the subjects followed for 5 years remained with low pVL (median = $0.36 \%$, range $0.05-1.43 \%$ ) and without changes in the WB profile.

\footnotetext{
* Correspondence: amangano@garrahan.gov.ar

'Laboratorio de Biología Celular y Retrovirus-CONICET, Hospital "J. P.

Garrahan", Ciudad Autónoma de Buenos Aires, Argentina

Full list of author information is available at the end of the article
}

\section{Conclusions}

Detectable HTLV-I proviral load in half of the cases with indeterminate WB profiles with positive PCR underlies the importance to conduct follow-up studies to evaluate the evolution of the infection.

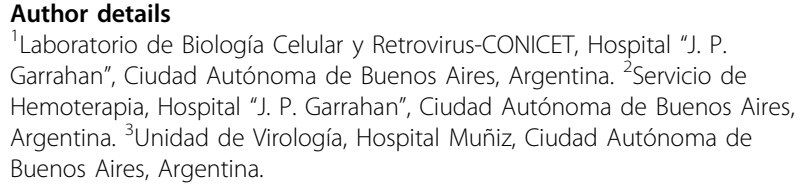
Garrahan", Ciudad Autónoma de Buenos Aires, Argentina. ${ }^{2}$ Servicio de Hemoterapia, Hospital "J. P. Garrahan", Ciudad Autónoma de Buenos Aires, Argentina. ${ }^{3}$ Unidad de Virología, Hospital Muñiz, Ciudad Autónoma de Buenos Aires, Argentina.

Published: 6 June 2011

doi:10.1186/1742-4690-8-S1-A245

Cite this article as: Mangano et al: HTLV-I proviral load in Argentinean subjects with indeterminate western blot patterns. Retrovirology 20118 (Suppl 1):A245.

\section{Submit your next manuscript to BioMed Central and take full advantage of: \\ - Convenient online submission \\ - Thorough peer review \\ - No space constraints or color figure charges \\ - Immediate publication on acceptance \\ - Inclusion in PubMed, CAS, Scopus and Google Scholar \\ - Research which is freely available for redistribution \\ Submit your manuscript at www.biomedcentral.com/submit}

